\title{
HOW DO WE PREPARE THE UK FOR A ZERO CARBON FUTURE?
}

MOST OF US ARE AWARE OF THE LOOMING THREAT OF CLIMATE CHANGE. ADDRESSING THIS GLOBAL ISSUE WILL TAKE DEDICATED ACTION AT INTERNATIONAL, NATIONAL AND LOCAL LEVELS. A SPECIALIST MULTIDISCIPLINARY TEAM OF RESEARCHERS WORKING ON THE IDLES PROGRAMME AT IMPERIAL COLLEGE LONDON IS USING THE LATEST TECHNOLOGY AND UNDERSTANDING TO DECIPHER HOW THE UK CAN TRANSITION TO A LOW CARBON ENERGY SECTOR WITHIN THE NEXT FEW DECADES

What will the world look like in 2050? The only certainty is that it will be radically different from today - climate change will lead to societal change, whether led by positive action or forced changes as a result of inaction. The former is infinitely preferable, but that involves rethinking virtually every aspect of modern-day life. One of the biggest questions involved is our energy system. Will we be relying on wholly renewable energy? Will petrol and diesel engines be a thing of the past? Will houses be heated by electricity rather than gas? Will we get our power from the national grid like today, or will the system have changed? Finding intelligent solutions to questions like these, and helping to set us on a path for a positive energy future, is what the IDLES programme is all about.

Since the Industrial Revolution, humanity has been pumping ever-increasing levels of greenhouse gases into the air. Much like a greenhouse, these gases trap heat energy from the sun within the Earth's atmosphere, making the world progressively warmer. This has big implications for society: increased risk of natural disasters, food shortages, biodiversity loss and widespread health impacts to name but a few. Despite there being clear scientific consensus behind these predictions, emissions have continued to show an increasing trend globally, with 33 gigatonnes of energy-related carbon dioxide $\left(\mathrm{CO}_{2}\right)$ emissions released in 2019 alone - the weight of 100 million Boeing 747s. It is clear that concerted global effort is needed to avert future catastrophe.

The UK has committed to reducing its share of these emissions, with more ambitious targets than many other nations around the world. The Climate Change Act, set up in 2008 and toughened in 2019 , legally
binds the government to reduce nationa greenhouse gas emissions to net zero by 2050. Teams of policy makers, investors, researchers and businesses are leaping into action to make this a reality, but it will be no easy feat. Bringing about the transition that is needed will only be possible with changes at every level of society.

\section{ASKING THE RIGHT QUESTIONS}

The electricity sector, plus the use of energy to heat buildings and power transport, accounts for close to two-thirds of the UK's greenhouse gas emissions. To fulfil the UK's goals, tackling the energy sector is an obvious target. However, as well as addressing emissions, it is crucial that people's needs are also taken into account - namely, that energy remains reliable and affordable far into the future.

Big changes are already underway. Renewable energy sources, in particular wind and solar, are contributing an ever-growing proportion of the UK's energy supply. There are strategies in place to phase out diesel and petrol engines from our cities. But to ensure these changes are seamless and do not lead to a dip in quality of life, we need to have a clear idea of the challenges we are likely to face and how to address them.

The IDLES (Integrated Development of Low-carbon Energy Systems) programme was set up to answer some of the biggest questions surrounding this transition. These questions include:

- What sort of energy scenarios would be feasible for 10, 20 and 30 years' time?

- How might people's future energy demands differ across the UK at different times? - How can we ensure a low carbon energy system is reliable and doesn't lead to power shortages?

- What role might emerging technologies play in the UK's energy future?

-Would it be sensible to shift the power network from a centralised grid to localised mini-grids?

- How can we make solutions cost-effective to consumers and attractive to investors?

- How can we persuade people to change their behaviour to low carbon energy solutions?

\section{WHAT ARE LOW CARBON ENERGY} SYSTEMS?

Unlike conventional energy systems, low carbon energy systems do not release large quantities of greenhouse gases, in particular $\mathrm{CO}_{2}$, into the atmosphere. We use energy in the form of heat, light and motion, amongst others, and since energy cannot be created, we have to transform it from something else. Releasing the energy stored in fossil fuels through burning is the conventional method, but we have increasingly sophisticated

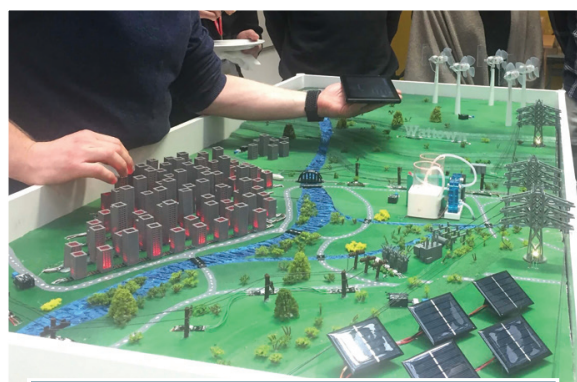

The 'Wattown' interactive demonstrator, built within IDLES for engagement events. It shows connected energy generation and storage options in a town of the near future. The town lights up when enough energy is supplied by solar panels and wind turbines, or provided from storage. 
technologies for extracting energy from sunlight, wind and other renewable or low carbon sources.

However, we cannot simply just swap fossil fuels for renewable sources and be done with it. There are a huge number of interconnected factors that need be considered, and we as people simply don't have the capacity to comprehend all of these at once when attempting to answer the questions above. Accounting for all these factors is known as a 'whole energy systems' approach and requires some hard science and powerful computation, which is where the IDLES programme comes in.

\section{MAKING A MODEL}

Discovering how all these different factors interconnect at the national level, especially as these interactions change in the future, is essential to ensuring a smooth transition. We cannot work this out through running experiments on the real world, because that would be hugely expensive and could put people's welfare at risk. The IDLES programme addresses the challenge through whole energy systems modelling: using sophisticated computer software to predict likely future outcomes based on the choices we could make today.

For example, take personal vehicles; most cars currently use fossil fuels to run, yet there is a range of pathways we can follow to transition away from this. Look at the table below. By plugging the 'scenarios' into a model, it can output detailed information about how these will interconnect with the rest of the modelled world.

\begin{tabular}{|c|c|}
\hline SCENARIO & POTENTIAL OUTPUTS \\
\hline Transition to electric vehicles & $\begin{array}{c}\text { Increased capacity of national grid to } \\
\text { cater to higher electricity demand; } \\
\text { the capability of 'vehicle-to-grid } \\
\text { technology' to support the national } \\
\text { grid using vehicles as 'batteries on } \\
\text { wheels'; recommendations of financial } \\
\text { encouragements for drivers to make } \\
\text { the transition a reality }\end{array}$ \\
\hline Transition to hydrogen-powered & $\begin{array}{c}\text { Development of ways to produce } \\
\text { and transport hydrogen safely and } \\
\text { efficiently }\end{array}$ \\
\hline Uptake of bicycles in urban areas & Changing urban road layouts to \\
prioritise cyclist safety
\end{tabular}

Of course, the actual model will give much more detailed and thorough outputs to these scenarios, and it is likely that different combinations of all the scenarios above will be applied in different regions at different times. In fact, a key feature of this modelling is that it can be applied both over broad time scales, from daily energy system operation to decades-ahead system planning, and across varying spatial resolutions, from towns or regions to national systems. Working out the optimal strategy on this fine-scale basis is complicated, which is why we need such sophisticated computer models.

The outputs the model provides can be hugely informative. For instance, they can help policy makers choose where to invest taxpayers' money; encourage investors to support a particular technology; inform manufacturers of where markets could exist for certain products; and even aid the general public who want to make sensible and responsible decisions in their daily lives.

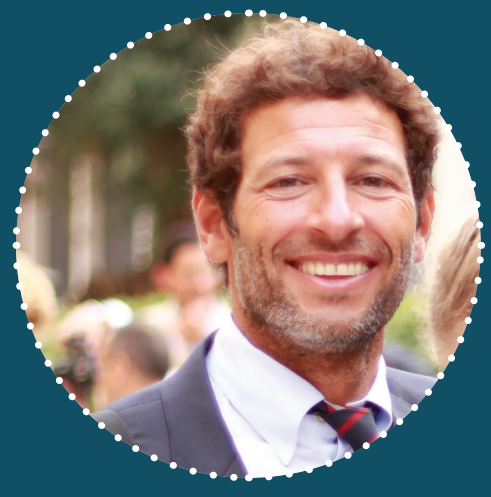

\section{DR ANTONIO MARCO PANTALEO}

Research Fellow

Department of Chemical Engineering

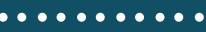

\section{BACKGROUND}

Electrical Engineering

\section{RESEARCH PROJECT}

Modelling future energy system scenarios for the UK; investigating the capabilities, performance and cost of existing and emerging technologies for energy systems

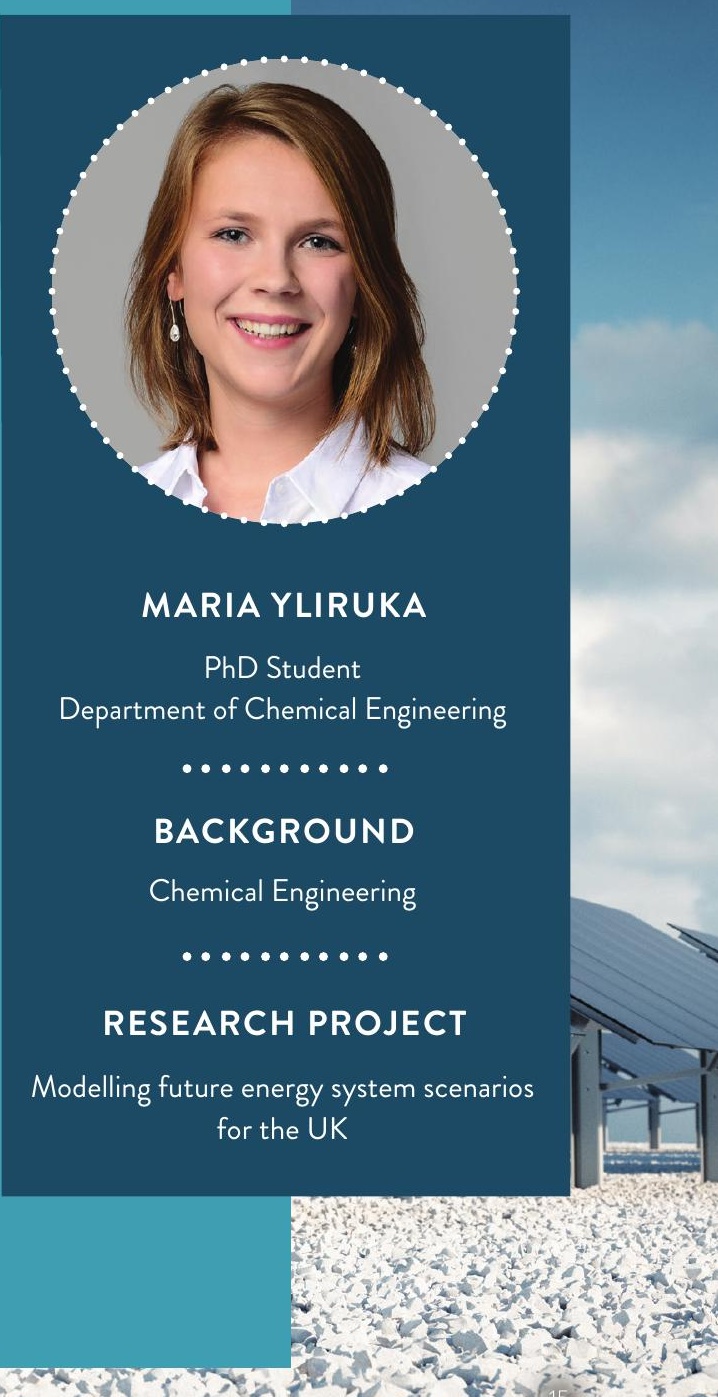

Modelling future energy system scenarios for the UK

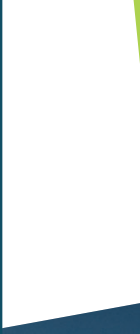




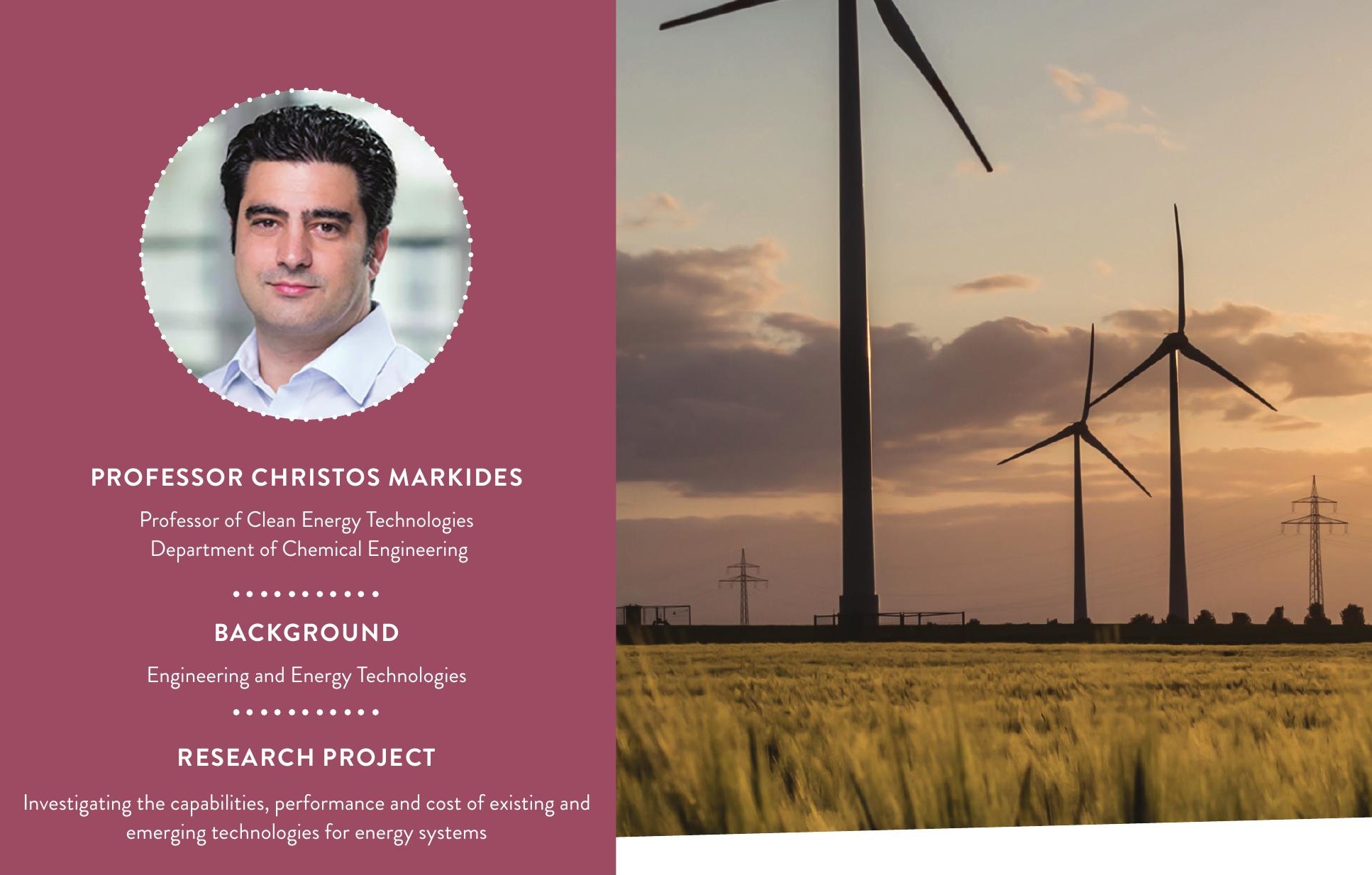

\section{AN INTEGRATED ENERGY FUTURE}

To make sure that the predictions from our computer models are accurate and reliable, the models need to be a good representation of reality, and inputs need to be carefully defined. Christos' project focuses on uncovering and describing the characteristics of different technologies within energy systems. This includes the physics behind energy conversion (e.g. from heat/motion to electricity) and energy storage (e.g. batteries). It also includes important details such as the performance, cost and likely future trends of all these different technologies, and how they interact. This information is then used within the whole-system computer models to identify the best and cleanest future energy system.
To be at their most efficient and affordable, energy systems need to be closely integrated. We cannot rely on any one form of energy or infrastructure, or on any one technology for generation or storage, but by interconnecting a multitude of them, we can create an optimised and resilient system. Storing electricity, for example, has always been difficult, and although batteries are becoming increasingly efficient and cheap, they are not a solution to all problems faced by the whole system. Examples of building in this interconnectedness to solve problems of a low carbon system are given below.

\begin{tabular}{|c|c|}
\hline PROBLEM & SOLUTION \\
\hline $\begin{array}{l}\text { No electricity being generated by wind and solar when there is no } \\
\text { wind, or during cold, dark nights, when electric heating is most needed } \\
\text { for homes. }\end{array}$ & $\begin{array}{l}\text { Integrated heat storage 'stores' excess energy during peaks of } \\
\text { electricity production (e.g. windy/sunny periods) by heating water in } \\
\text { tanks. This water can then be used in homes later, when needed, for } \\
\text { heating or hot water. }\end{array}$ \\
\hline $\begin{array}{c}\text { High energy demands for cooling large data centres and heating } \\
\text { homes. }\end{array}$ & $\begin{array}{l}\text { Excess heat from data centres is transferred to homes, solving both } \\
\text { issues. }\end{array}$ \\
\hline $\begin{array}{c}\text { Some homes still have gas-based heating/cooking systems, but the } \\
\text { use of natural gas does not fit zero carbon targets. }\end{array}$ & $\begin{array}{l}\text { Excess electricity (e.g. during sunny/windy periods) can be used to } \\
\text { create hydrogen via electrolysis of water, which can then be combined } \\
\text { with carbon dioxide to produce methane as a substitute natural gas. }\end{array}$ \\
\hline $\begin{array}{l}\text { The consumption of electricity outstrips the generation of electricity } \\
\text { on cloudy, still days. }\end{array}$ & $\begin{array}{l}\text { 'Vehicle-to-grid technology', where electric vehicles plugged into the grid } \\
\text { act as batteries, and can have electricity drawn from them during peaks in } \\
\text { demand. Vehicle owners could also receive monetary compensation. }\end{array}$ \\
\hline
\end{tabular}




\section{SMART DECENTRALISED ENERGY SYSTEMS}

Renewable sources of energy make localised electricity generation a real possibility. It is very difficult (not to mention undesirable) to have a miniature coal-fired power station in your backyard for your own personal use, but alternatives like solar panels are far more feasible. Already, excess energy from home-owned solar panels can be sold to the grid, and there is no reason why the same principle cannot be applied at a local level. Communities could have ownership over their energy sources, which could even let them set their own energy prices and trade energy. Regional grids are also critically important for a future low carbon system, by enabling transport of renewable energy produced by large-scale, offshore wind farms. Local flexibility technologies and control systems will be key for real-time balancing of demand and supply. For instance, hot water tanks and electric car batteries (via vehicle-to-grid) can act as temporary energy storage units, which can help ensure that supply and demand are always in balance. With the arrival of 'smart' energy use, homes could even make their own decisions, such as not running the dishwasher during times of peak demand.

\section{A RESILIENT ENERGY SYSTEM}

With the advent of climate change, there is a growing need to be able to deal with extreme weather conditions, which could knock out national transmission lines and lead to major power outages, for example. Ensuring that people are not left without energy is one of the key challenges to transitioning to a low carbon energy system. One way to address this challenge is to transition from megagrids to microgrids. Megagrids disperse energy from power stations and other large sources of energy from a centralised point. Should this large, centralised point be disrupted by extreme weather events, many homes across the UK are at risk of losing their energy supply, causing major health and safety problems. Microgrids, on the other hand, offer a low-cost and advanced intelligent solution to delivering secure and resilient energy. With the right enabling technologies, including information technology and communication infrastructure, microgrids will be able to operate independently across smaller, more localised areas, and significantly enhance resilience of the electricity supply.

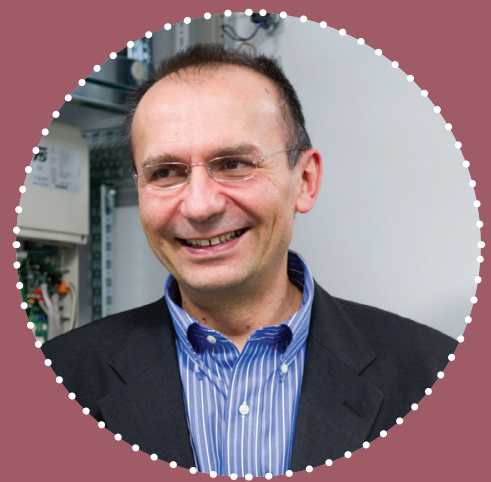

PROFESSOR GORAN STRBAC

Chair in Electrical Energy Systems

Department of Electrical and Electronic

$$
\text { Engineering }
$$

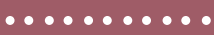

\section{BACKGROUND}

Electrical Engineering

$\ldots \ldots \ldots \ldots$

\section{RESEARCH PROJECT}

Investigating how to incorporate resilience into low carbon energy systems

\section{UNCERTAINTY, AND HOW TO MANAGE IT}

Historically, the energy system in the UK has been upgraded on a 'like-for-like' basis. For instance, if a power line failed, it was replaced by a similar one. The same goes for entire power plants. Even new investments have tended to look only to the short term, designed to cover the needs of the next few years rather than far into the future. However, with a major systemic transition in the works, this approach won't be adequate.

With energy demands changing radically, investments now need to look decades ahead instead of just a few years, but investors are cautious creatures - so how can uncertainty be factored in successfully?

Models can factor in this uncertainty and map out alternative realities. Not only can they predict the likelihood of particular outcomes, they can also inform us of what inputs make these outcomes more or less likely. For instance, if you are a potential investor in a renewable energy project and learn that your investment makes the project far more likely to succeed, chances are this will make you far more likely to invest.

Credit: Stefano Moret and Outi Supponen

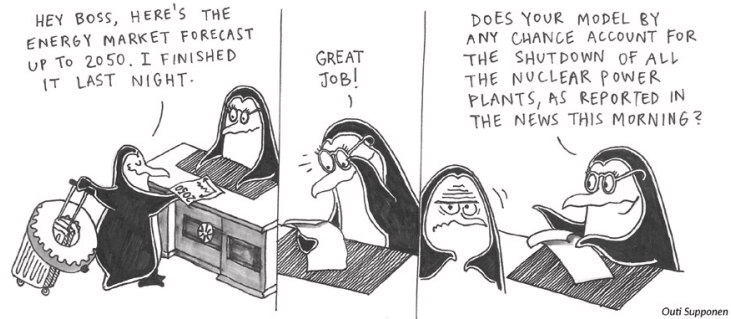

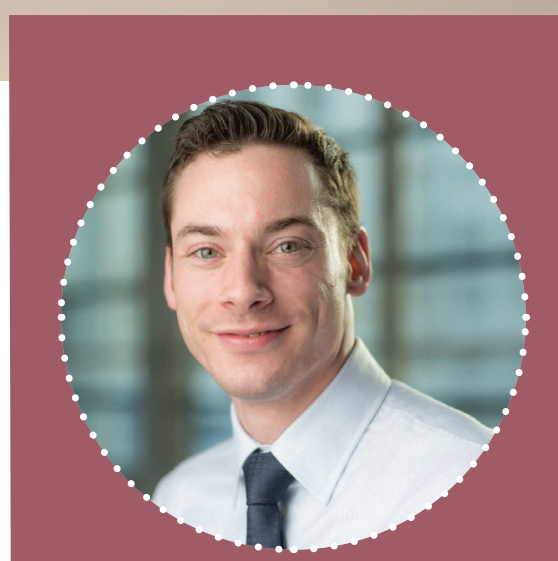

\section{PROFESSOR WOLFRAM WIESEMANN}

Professor of Analytics and Operations Imperial College Business School

Computational Optimisation Group

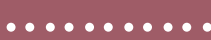

\section{BACKGROUND}

Mathematics, Management and Computing

(...........

\section{RESEARCH PROJECT}

Accounting for uncertainty in decisionmaking for future energy scenarios 


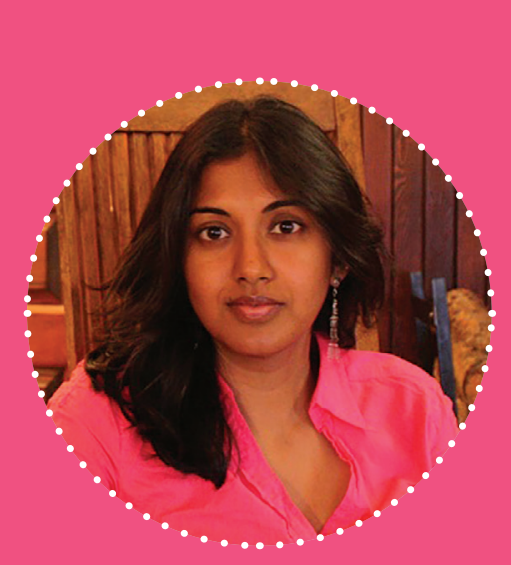

DR ARUNA SIVAKUMAR

Senior Lecturer in Smart Cities and Demand Modelling, Department of Civil and Environmental Engineering

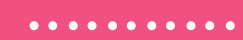

\section{BACKGROUND}

Transportation Engineering

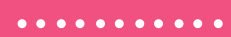

\section{RESEARCH PROJECT}

Understanding changing energy demands and interplay with reliability in low carbon

systems; and developing models for predicting energy demand in different policy scenarios

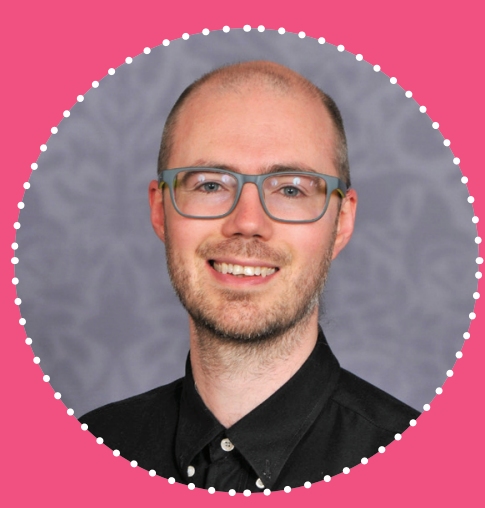

DR IAIN STAFFELL

Lecturer in Sustainable Energy Systems

Centre for Environmental Policy

BACKGROUND

Physics, Chemical Engineering and Economics

\section{RESEARCH PROJECT}

Uncovering the economic implications of future low carbon energy system scenarios

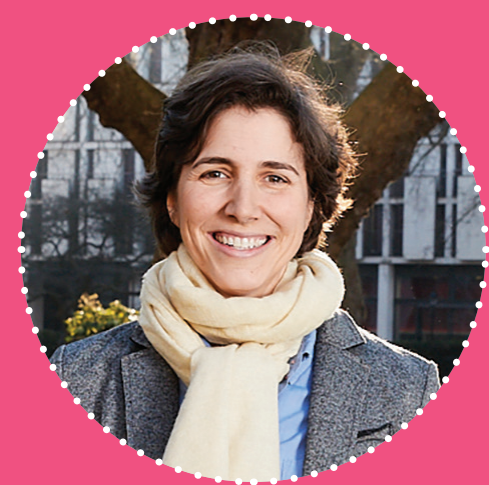

\section{DR MIRABELLE MUÛLS}

Assistant Professor in Economics Imperial College Business School

\section{BACKGROUND}

Economics

$\cdots \ldots \ldots \ldots$

\section{RESEARCH PROJECT}

Exploring how and why people and businesses change their energy demand

the intent is that this will lead to energy-saving changes in our behaviour. As advances in wireless technology allow increasing interconnectedness between devices (the so-called 'Internet of Things'), the smart meter system could become even smarter. It could, for example, automate certain technologies: when the wind is not blowing and energy prices are peaking at a time of high demand, the smart meter could pause the charging of an electric car.

This could also be the case for larger structures, such as offices or factories, as well as their fleet of electric vehicles. A household or a business could even be paid for reducing consumption at peak times in order to reduce the load on the electricity grid. This is called Demand Side Response. Small changes in demand at peak times would mean that the whole system could be less carbon intensive, by not having to produce energy for demand surges.

\section{ECONOMICS, AND THE CHOICES WE MAKE}

While models can calculate various scenarios and what they mean for society, there is also the need to test the economic logic of such scenarios. Energy systems are complex, and their long-term evolution is the collective effort of private firms and public bodies. Government regulations and interventions have a significant influence, but changes also depend on utility companies, network providers, building developers and end consumers. All of these have a part to play in a transition, and all their decisions are influenced by economics.

The role of consumers could change dramatically if we move from today's centralised energy system to a decentralised approach with small, local grids. Consumers could get a financial reward if they lower their energy consumption at times of peak demand (e.g. by delaying when they wash laundry). This flips the traditional mantra that supply is dictated by demand - now, with consumer cooperation, demand could adapt to follow the peaks and troughs of renewable energy production.

This is the sort of market change that lain's project is investigating. It involves pinpointing the needs of customers, investors and wider society now and in the future, to design a low carbon integrated energy system that caters for all. It takes the outcomes from the programme's computer models and works out how they could be economically viable; whether the transition could work under current markets, or whether innovative economic thinking is needed to facilitate this change. 


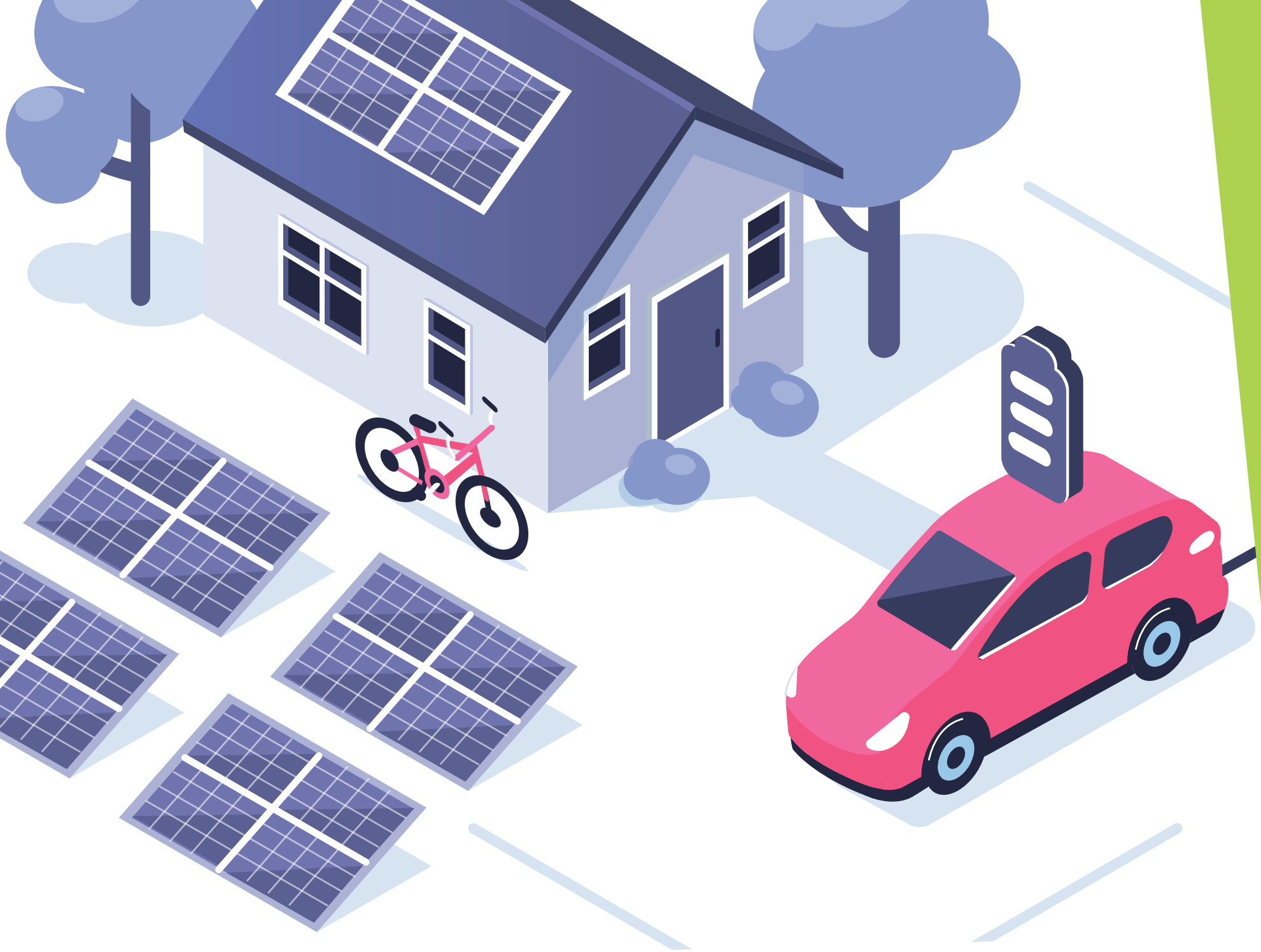

\section{OPPORTUNITIES AND CAREER PATHWAYS}

The researchers involved in the IDLES programme come from a very diverse range of backgrounds. Rewriting a national energy system is no small task, and many different disciplines are needed to tackle it fully. Here, the researchers talk about their academic backgrounds and how they helped them get where they are today.

MARIA: Chemical engineering gives you a great understanding of low carbon technologies like batteries and fuel cells, and how they might look in the future. Balancing so many mass and energy equations will let you master energy systems!

CHRISTOS: Engineering is the natural answer to physical challenges, to how things work and how they could work better. It gives the pathway for science to be applied and have an impact on society. Engineering is a broad field, spanning from the largest machines to the tiniest microchips, all affecting daily life around the world.

ARUNA: Transportation engineering is a very inter-disciplinary field, and at universities can also be covered within the geography or the urban planning department. I develop tools to predict demand by drawing on an understanding of human behaviour, which involves research in psychology, sociology and economics. Pulling these into mathematical models is crucial for predicting future trends and informing government or business policy.

MIRABELLE: Economics analyses the choices that people make with limited resources. Both individuals and businesses consume energy, and this consumption is the result of economic choices. Economics gives us the tools to understand these choices and make predictions to inform policy and infrastructure design.

GORAN: Electrical engineering is an exciting field to be in at the moment. We are transitioning to a low carbon energy system, which means there is plenty of interesting work for electrical engineers. In the area of system modelling, for example, we are investigating innovative ideas for transitioning to smart digitalised grids, to enable cost-effective energy system decarbonisation.

WOLFRAM: Mathematics allows us to take something complex in the real world, such as our energy system, and reduce it to a manageable model that retains all the important parts. We can then use computers to predict how our choices today might affect the future. This is an immensely powerful tool. 